\title{
Evaluation of Quality during Construction Projects: A Case Study of Pakistan
}

\author{
AMMAD HASSAN KHAN*, ALI IMRAN**, AND MUZAMIL HUSSAIN*** \\ RECEIVED ON 17.08.2017 ACCEPTED ON 12.02.2018
}

\begin{abstract}
Achieving and maintaining quality values are indispensable for attaining organizational and customer satisfaction. This research investigates different aspects of operationalize quality culture and factors affecting the quality of building construction in under developed countries like Pakistan. A qualitative and quantitative survey was circulated among different stakeholders including Clients, Consultants and Contractors to assess the level of the contractor's performance, the project monitoring and controlling techniques, proper health and safety requirements, client satisfaction and workers experience in construction industry projects. The practice of professional quality management in building projects is increasing, however, many flaws and negligence are still found in local practices. This analysis also indicates that political and socio-economic factors play a significant role in maintaining the quality level in local industry. Therefore, the allocation of sufficient resources, proper training of workers, and recruitment of quality control staff and the use of advanced technologies are recommended for proper implementation of QMS (Quality Management System).
\end{abstract}

Key Words: Construction Industry, Quality Management System, Quality Control, Contractor Performance, Customer satisfaction.

\section{INTRODUCTION}

s the complexity and size of building projects
is expanding, the clients are demanding higher contractors are also keen to adopt the high quality standards in organizations to improve the competitiveness, overall performance and to reduce the relative project costs [2-3]. The implementation of QMS in construction is unending process and needs continual improvements with modifications [4]. Hence, it is pragmatic to inspect the sustainable performance from the capability of implemented management system and the authenticity of process throughout the building construction lifecycle [5]. The high level of the performance can only be achieved through quality control of each process. However, several flaws such as incompetence in contract management, lack of

Authors E-Mail: (ammadhk@hotmail.com, aimranyaseen@gmail.com, muzamilhussain833@gmail.com)

* Faculty of Civil Engineering, University of Engineering \& Technology, Lahore, Pakistan.

* $\quad$ Infrastructure Development Authority Punjab, Pakistan.

*** Department of Technology, The University of Lahore, Lahore, Pakistan.

This is an open access article published by Mehran University Research Journal of Engineering and Technology, Jamshoro under the CC by 4.0 International License. 
professional planning, deficiencies in control of project, slow decision capability, inefficiency in leadership and execution of non-standard methods have been indicated in construction industry [6-7]. So it is important to focus all phases of building construction to understand the factors that affect the quality of project [8-9]. It is also required to elaborate the role of management, quality assurance system and its applications in different aspects [10-11].

Several studies have focused on innovative tools [12], integration management capabilities [13] and project management factors [14] of construction firms. Chou et. al. [15] proposed a model where the combined effects of quality, project scope, communication, time, risks, procurement management and human resources for success of construction projects in Indonesia, Taiwan and Vietnam are investigated. It is concluded that the effective use of knowledge of project management body assures the project success. A study [16] on the basis of BIM (Building Information Modeling) is conducted on urban complex construction projects in china. It is proposed that the quality of urban complex construction projects should be improved by using the BIM information sharing functions and features. Lukichev et. al. [17] discussed the facing problems of QMS implementation and certification body selection in Russia. It is suggested that the competitiveness in global market may be improved after obtaining the certificates of foreign certification authorities such as ISO-9001:2015. Poyhonen et. al. [18] described a real school project from Finland and developed PDS (Project Delivery System) using innovative management system. It is determined that the resources and competences, market input, development process and strategy are main parameters for developing PDS. Kozlovskaa et. al. [19] conducted a survey in Slovakia and concluded that not only the costs, quality and time are essential for construction management, but also the planning of construction equipment, safety factors and seasonal impacts must be included in documentation. Memon et. al. [20] also circulated a survey in two major cities of Pakistan to know the level of QMS in construction projects. The results of this study show that both consultants and contractors are showing the negligence in implementation of QMS, although they understand the significance of QMS. However, the objective of this research is to perform a comprehensive analysis of operationalize quality culture and the factors governing the quality assurance during building construction in Pakistan.

\section{CATEGORIZING QUALITY CONTROL PARAMETERS ON THE BASIS OF LITERATURE REVIEW}

QC (Quality Control) culture is the valuable system of any organization that encourages workers to establish quality environment. It promotes and improves quality with the continuous practice of attributes, procedures and traditions. The $\mathrm{QC}$ culture helps the contractor to meet the required competitive business performance, client satisfaction and social responsiveness [2-14]. The collective effect of several resources such as human, QC standards, material, machinery, procedures and environment defines the effectiveness of QC process or quality management system in construction industry [2526].

\subsection{Human Control}

The most important factor of QC is human ability. More efficient and skilled staff can produce high quality work. Human has ability to control himself and things such as 
quality can be controlled from him [27]. The momentum of whole management system depends on the combined effort or team work. The failure or success of any organization depends on caliber of leadership [28].

\subsection{Quality Control Standards}

It is considered that the important factor for the success of any organization is in implementing QMS as it has ability to integrate, translate and institutionalize the QC behaviors in everyday practices [29]. The implementation of any defined standard ultimately changes the culture, strategic priorities, process and beliefs of organization. ISO provides world-class specifications for all types of products, projects and services to ensure safety, efficiency and quality [30]. ISO provides strategic guidance and tools that help organizations to minimize the errors, access the new market demands and increase the productivity [31]. The number of fundamental principles of quality management including implication and motivation of higher management, customer focus, continual improvement and process approach are used to achieve customer's requirements and quality consistently [32].

\subsection{Selection of Optimal Process and Materials}

The selection of materials according to design and environmental requirement is most significant task that determines the quality of construction directly. It is important for each contractor to ensure selection of materials according to the application, design, cost, environmental conditions and performance before purchasing [33]. The procurement of materials needs to be completed before its implementation. The environmental conditions, dimensions of specimens, selection of tool, several loading and stress conditions, method of tests, objective of tests and consideration of particular use etc. are required for investigating the characterization of materials [34]. The selection of optimal alternative process and method is mandatory.

\subsection{Other Parameters Influencing the Quality Management System}

Health and safety assurance, planning and scheduling, motivation and security of employees, evolution of technology, external and internal audits, research and development, political influence, integrity of workers, budget volume and tender requirements are some other factors that affect the quality [35-36].

\section{MATERIALAND METHODS}

A questionnaire survey is developed on the basis of factors as mentioned in section 2. Complete questionnaire is given in the Appendix-I. The description of questionnaire format and methodology for data collection and analysis is discussed in the following section.

\subsection{Questionnaire Format}

This research is carried out in the construction industry of Pakistan. For present study, the mixture of qualitative and quantitative approaches have been adopted. Quantitative research is used to collect and transform specific data that is used to evaluate. Qualitative research gives respondent to express views openly and their suggestions or views lead to modify and expand the boundary of results during the analysis. For this survey, several types of thirty-five (35) questions were included for the development of questionnaire. The brief description about the pattern of questionnaire is discussed in following points. 
- $\quad$ Closed ended format include the set of multiple choice questions. Such type of questions forced the respondents to select answer from any of the given choices.

- Open ended questions provide opportunity to our respondents to express their views freely.

- The set of liker questions helps the surveyor to know how strongly the reviewers agree any particular issue or statement.

- Dichotomous questions allows the reviewers to choose the only one option either yes or no, agree or disagree.

- $\quad$ Rating scale questions allow the respondents to rate any specific issue between good to poor.

- The closed ended, open ended, liker, dichotomous and rating scale questions are included in questionnaire and divided into following four sections.

(i) Organizational profile.

(ii) Common QC practices in construction sector.

(iii) Respondent's experience with QMS.

(iv) Remarks and suggestion.

The first section of the questionnaire was designed seeking organizational and personal information of the respondents. The research was a technical oriented one. So, the professionals for survey were selected from the construction industry, especially the people responsible and related to quality management and control at construction sites. This section of the questionnaire inquired about the experience, type of organization, position in the organization and their educational level. The second section of questionnaire was designed especially, to assess the awareness about the QC methods, techniques and standards. The general QC practices considered in survey are described in Fig. 1.

In third section of questionnaire the quality of construction techniques and material used for construction of buildings was inquired. The questions related to other parameters are also included to assess the performance of contractors. The complete details of variety of questions included in survey are briefly listed in Fig. 2.

\subsection{Data Collection}

The data for this research is collected in 1.5 years ranging from 2016-2017. For present study data was collected via emailing questionnaire to the respondents (experts). A total of 110 questionnaires were sent through email to experts/professionals of construction industry within the

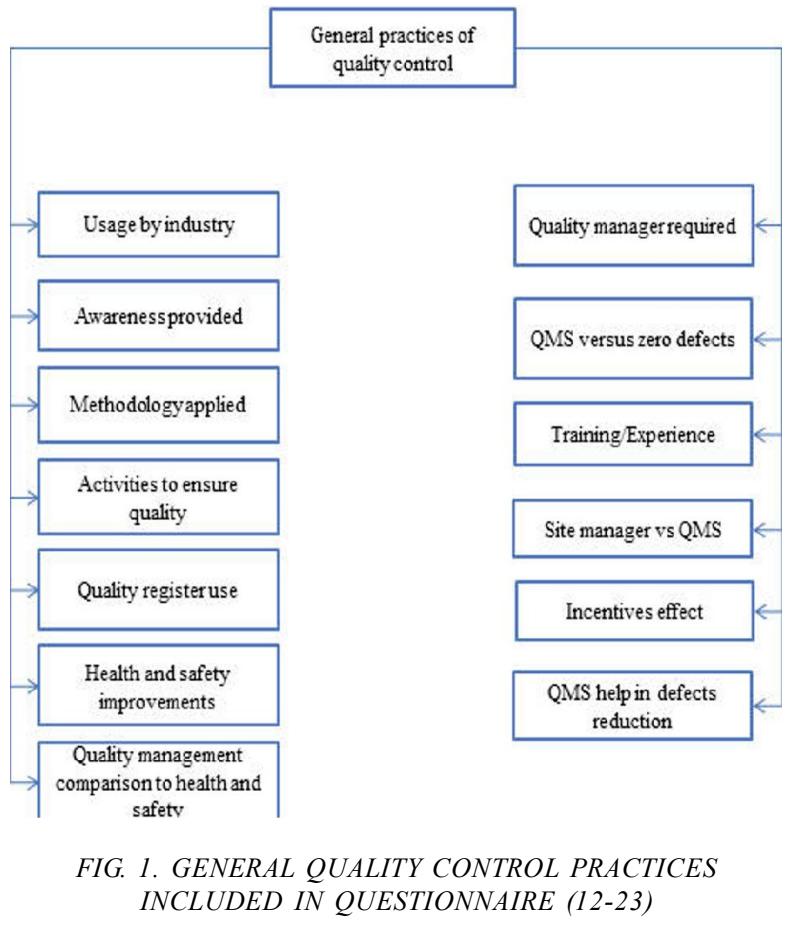

Mehran University Research Journal of Engineering \& Technology, Volume 38, No. 1, January, 2019 [p-ISSN: 0254-7821, e-ISSN: 2413-7219] 
region of Punjab, Pakistan to achieve the target of hundred. 94 responses were received, which were then inspected for non-responsiveness and incompletion. After scrutiny of these 94 respondents four participants were observed biased and the responses of these four were discarded; this resulted in a total of 90 complete and robust responses. However, these remaining ninety questionnaires were satisfactory, so the results were evaluated on the basis of their responses.

\section{RESULTS AND DISCUSSION}

The findings of the research are discussed below:

\subsection{Organizational Profile}

The position in organization, organizational background, education and experience of the respondents were investigated in this section. The designation or the position of the respondents in the organization was asked in first question. Four directors, eight project managers, thirty-six site engineers, ten QC engineers and 32 other employees are contacted to compare and verify the responses and to differentiate the views of higher and lower body. The workers of several ranks are targeted, however, maximum number of site engineers have participated in survey because of the fact that they play more significant role to control the quality at the building construction projects and only limited companies preferred to hire the QC engineer for each site. From question 2 it was found that $43 \%$ employees of contractors, $36 \%$ employees of consultants and $21 \%$ employees of clients are participated in the survey. However, it was preferred to contact more persons of contractor firm because contractors were involved directly in construction phase. First of all, it is the responsibility of contractors to use the QMS and standards to maintain

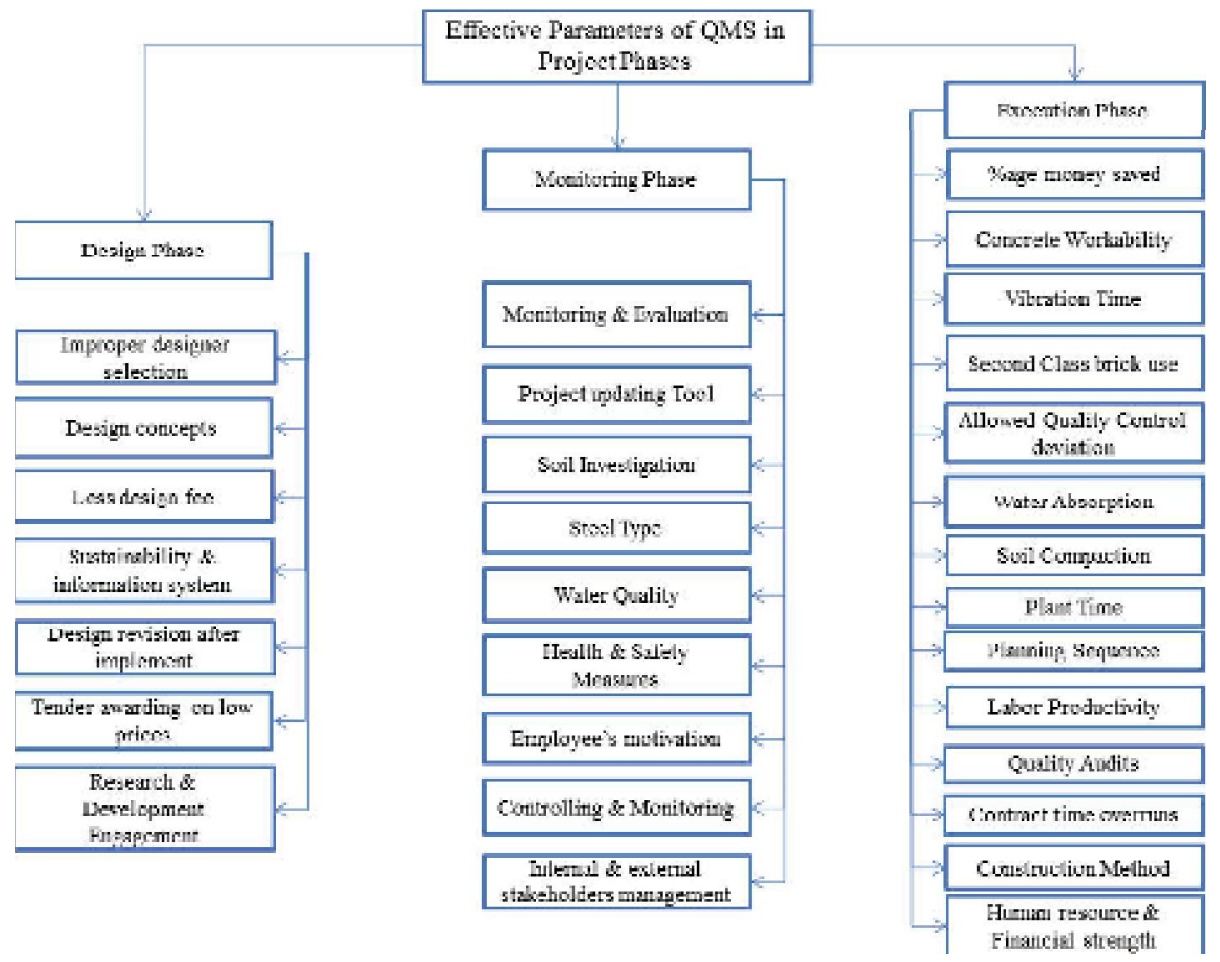

FIG. 2. PARAMETERS OF QMS IN CONSTRUCTION PROJECT PHASES [21-37]

Mehran University Research Journal of Engineering \& Technology, Volume 38, No. 1, January, 2019 [p-ISSN: 0254-7821, e-ISSN: 2413-7219] 
the quality. As the instructions of clients and pressure of consultants also play significant role in QC. So, the reasonable strength of clients and consultant firms are also included in survey.

The statistical data of question 3 shows that the qualification of $65 \%$ participants was BSc. Engineering, 28\% were MS Engineering and 7\% were diploma holders.

It is investigated that most of the respondents were BSc Engineers having experience less than five years. The statistical data of experience is presented in Fig. 3. Although they have less experience but they have more potential to face the work pressure. But the gap among experienced and highly qualified individuals could not minimized.

\subsection{Common Quality Control Practices in Construction Sector}

This section of questionnaire was designed essentially to assess the awareness about the already implemented QMS, techniques and standards. From question 6 and 7, it is concluded that majority of employees agreed that they are using QMS in construction field and they are advised to maintain it. However, further investigation shows that the only thirty-two respondents are using international standard, however, remaining are following

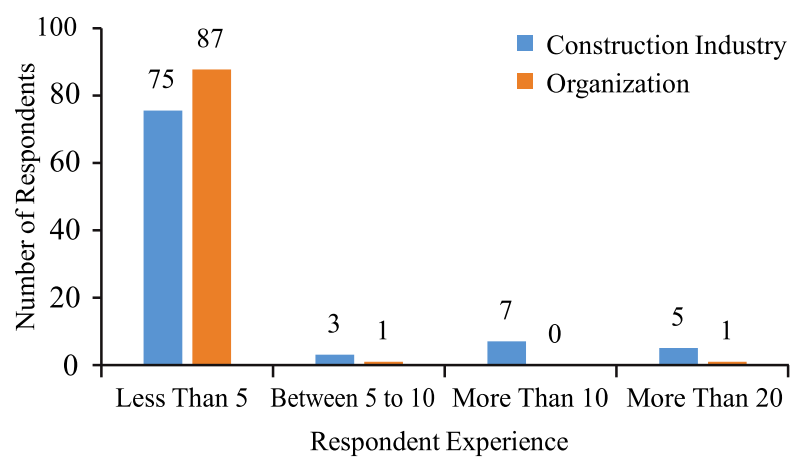

FIG. 3. WORK EXPERIENCE OF RESPONDENTS the local approaches such as twenty are using the client based Performa, sixteen are using the checklist, and fourteen are using the specialist subcontractor system. The more important finding is that three respondents accepted that they are not using any QMS and never received any instruction from higher management about it. Hence, we can conclude that the practice of QMS is increasing but few are still not interested in such activities. The frequency of quality register is also determined in one question to examine the consciousness of respondents in QA (Quality Assurance). The statistical data shows that $52,7,16$ and $3 \%$ are using quality register weekly, fortnightly, monthly and sporadically respectively. The 22\% respondents claimed that they never used quality register. From this data it is concluded that if they are not using this basic activity then the situation concluded from above question is probed. Fig. 4 shows the data of two questions in which the indirect relationship of health \& safety with QMS is investigated.

It is found that most of organizations are aware of the importance of availability of quality manager. The overall response of respondents shows that the implementation of the QC system is mandatory to minimize the defects in project. However, enough time is required on QA of activities in a typical working week. Instead of this, it is

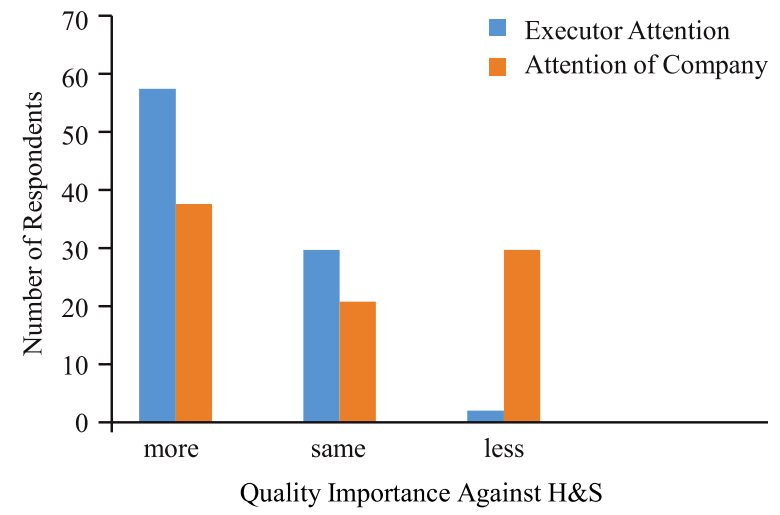

FIG. 4. IMPORTANCE OF HEALTH \& SAFETY 
also investigated that the proper quality management training in whole organization, site management training and QMS incentives are fruitful for the improvement of quality. This is concluded from the questions 13-19 which is presented in Table 1. Fig. 5 shows that most of the statistical scores are greater than 20 points of mean value.

\subsection{Experience of Respondent in Quality Management System}

The method of construction activities and quality of materials used for construction of buildings are investigated in this section. In first question it is investigated that almost all the respondents believed that $5-15 \%$ total cost of project can be saved by proper QC management. On the basis of this concept we can analyze that most of the organizations are meeting quality measures as minimizing the cost of project is the first priority of every organization. From the data of next question as shown in Fig. 6, it was found that many organizations preferred to add $0.5-2 \%$ extra water to increase the workability of concrete. This practice represents that many firms show the flexibility to deviate the standard. Similarly, Vibrator time for the proper compaction of concrete is inquired to assess the level of perfection in concreting. It is found that fifty-four companies are using $2 \mathrm{~min}$, three are using $3 \mathrm{~min}$, sixteen are using greater than $3 \mathrm{~min}$ and one is not considering vibrator. Scheduling and monitoring of project after design is the most significant component of project life cycle. The analysis shows that $76 \%$ respondent's start planning and monitoring at the start of the project, while $18 \%$ plan it during execution of project, $1 \%$ plan it at the end and 1\% do not do it. Primavera (P6) software package is most widely used in Pakistan for project planning as sixty respondents claimed that they are using it but remaining twenty-three are still using the Microsoft office and five are using the PERT for that purpose.

Bricks are the most important building material in Pakistan, some reasonable respondents up to thirty-

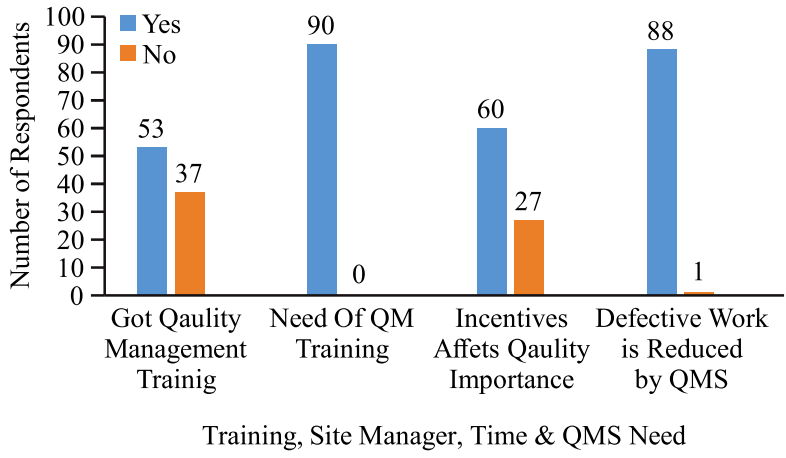

FIG. 5. IMPORTANCE OF QUALITY MANAGEMENT AND QUALITY MANAGER TRAINING \& QMS INCENTIVES AND REDUCTION OF DEFECTIVE WORK

TABLE 1. NEED OF QUALITY MANAGEMENT SYSTEM \& TIME FOR QUALITY ASSURANCE

\begin{tabular}{|c|c|c|c|}
\hline \multicolumn{2}{|c|}{ Requirement of QMS } & \multicolumn{2}{c|}{ Enough Time is Needed to Spend on QA } \\
\hline Status & Number of Respondents & Status & Number of Respondents \\
\hline Strongly agree & 44 & Strongly agree & 37 \\
\hline Agree & 45 & Agree & 43 \\
\hline Neutral & 0 & Neutral & 0 \\
\hline Disagree & 1 & Disagree & 0 \\
\hline Strongly Disagree & 0 & Strongly Disagree & Mean: $17.4 \&$ Standard Deviation: 20.9 \\
\hline
\end{tabular}

Mehran University Research Journal of Engineering \& Technology, Volume 38, No. 1, January, 2019 [p-ISSN: 0254-7821, e-ISSN: 2413-7219] 
two accepted that they are using 1-20\% second class bricks of total bricks. However, 52 respondents claimed that they are not using second class bricks. Remaining four accepted that they are using more than $20 \%$ second class bricks. Water absorption test is used for the inspection of bricks. 35\% respondents claimed that they used the bricks even when the absorption power is greater than $20 \%$, while $21 \%$ claimed that they never performed the water absorption test. From these facts we conclude that majority of our industry is not properly adopting the standards especially where they find any benefit related to money saving. It is not an easy task to achieve the $100 \%$ perfection in results when we compare with standard values. So, it is common practice to accept any process or material with little tolerance. But acceptance of greater fluctuation show that we compromise on quality. The statistical data of one question shows that the thirteen out of seventy respondents accept the tolerance greater than 5\%. The soil tests were performed in execution that directly determines the quality of compaction. In question 27 it was asked either soil investigation test performed or not at the site. Almost all the respondents perform soil investigation tests on the site. In one question the value of soil compaction for the determination of strength of soil is investigated

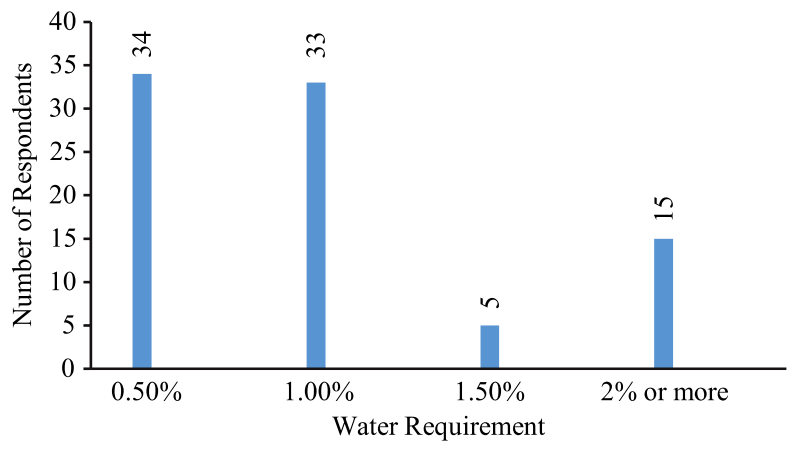

FIG. 6. WATER REQUIRE TO ATTAIN WORKABILITY as shown in Fig. 7. In next three questions many points were considered about the quality of concrete. One of question was about the compressive strength of concrete. The maximum strength of concrete achieves after 28 of casting. Forty-Four (44) participants claimed that they performed the tests; however, remaining claimed that they performed testing after the 14 and 7 days. Concrete gives maximum strength at 28 of its casting. The proper proportion and mixing of concrete with mixers also plays important role in concrete quality. One question was about the mixing time of concrete. Twenty-eight respondents claimed that they mix the concrete for 1 min; thirty-six accept that they do the same process 2 minutes and remaining accept that they mix the concrete more than 3 minutes. The behavior about the testing of concrete under tensile loading is also investigated in another question as shown in Fig. 8 . It is found that the majority of people are not performing the tensile tests. It is a fact that the companies that focus on high level quality cannot neglect any material testing procedure even that these tests are not more beneficial. Steel of different grade may be used in construction; therefore, the question was asked about the preference of steel bar during selection. It is found that mostly persons up to $63 \%$ are using hot rolled steel of grade 60 while remaining

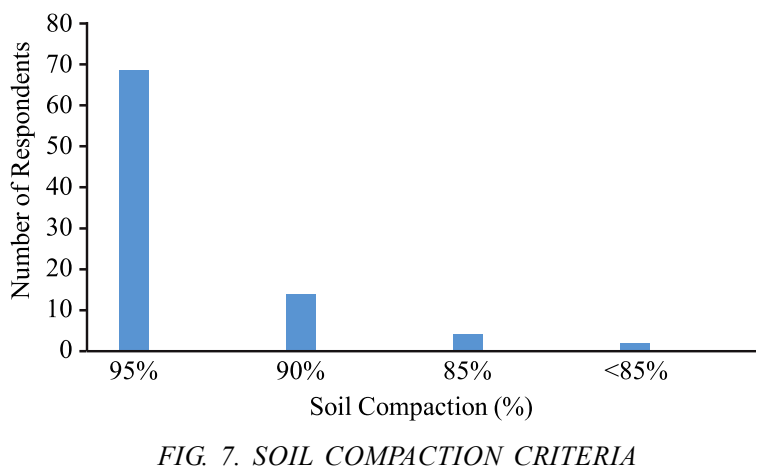

Mehran University Research Journal of Engineering \& Technology, Volume 38, No. 1, January, 2019 [p-ISSN: 0254-7821, e-ISSN: 2413-7219] 
are using the steel of other grades such as grade 60 grade cold twisted, grade 40 hot rolled and grade 40 cold twisted steel. The preference of water quality used in mixing is investigated in one of the question and it is found that $79 \%$ respondents use the tap water, $11 \%$ used the distilled water, $2 \%$ used water of any quality and remaining $8 \%$ never checked the quality of water. From the result of this section we conclude that where many companies are following the standard values but few do not care the standard values.

\subsection{Suggestions by Respondents}

The section of suggestions by respondents have been included to know the opinion of respondents about the improvement of QC. The purpose of this section was to give the opportunity to respondents to express the views freely about anything such as questionnaire, impact of survey, implementation of QC management system, techniques for the improvements of QMS, hurdles in QC or any other related issue. Because it was time taking process so only few respondents filled this section. Comments of few respondents are discussed in following paragraphs.

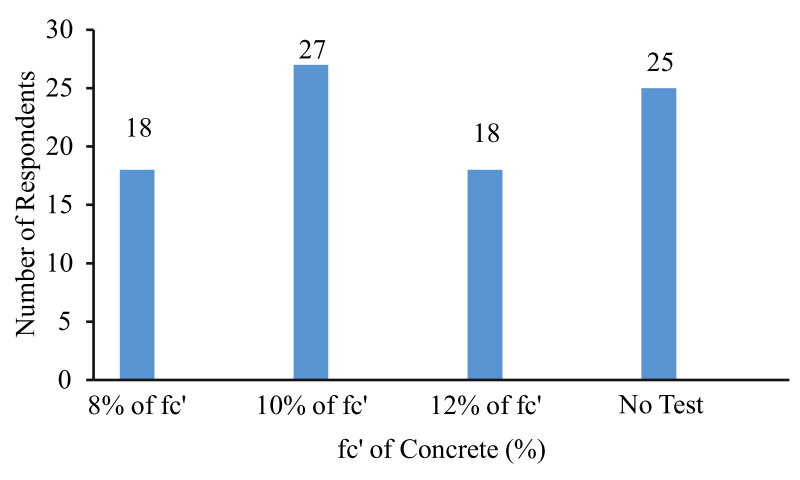

FIG. 8. TENSILE STRENGTH OF CONCRETE
Few respondents highlighted that the selection of good quality materials is the first and important step for the QA. And then fair supervision of projects according to the standards is required. As construction projects are completed after the huge investment and long duration so any carelessness or corruption may not be acceptable from supervisors, contractors and client. However, the complete control of materials quality and implementation of QC management system with seriousness and sincerity will be possible if the anti-corruption departments will take action against corruption. Hence it is need to improve whole system for safety and quality measurements. For this purpose, the department of QC under the supervision of quality manager is mandatory to manage $\mathrm{QC}$ activities and resolve issues. Also, honesty and loyalty of staff is important to ensure the implementation. So, if employees of organization will not compromise against their integrity and ethical values and whole society will play their role then it will be easy task.

Awareness and Competence about methods of QC, Regular Inspection \& Testing, Corrective and Preventive action and Internal and External Audit must be considered for QA. In Pakistan contractors always find shortcuts to avoid the proper standard methods. Sometimes quality managers also compromise on proper standards. Mostly countries develop their own standards. So, it is better for us to develop the standards. Moreover, proper training and knowledge of IS is required. The use of QC tools, qualitative resources and skilled workforce plays strong role in QMS. The forecasting about the project management, resources and cost must be on the basis of realistic factors. 


\begin{tabular}{|c|c|c|}
\hline \multicolumn{3}{|c|}{ APPENDIX-I: SAMPLE QUESTIONNAIRE } \\
\hline \multicolumn{3}{|c|}{ Questionnaire Survey } \\
\hline \multicolumn{3}{|c|}{$\begin{array}{c}\text { I am doing a research on "Evaluation of quality control practices during building construction projects in Pakistan". Your kind responses for the } \\
\text { Following questions will be much appreciated. }\end{array}$} \\
\hline \multicolumn{2}{|r|}{ Name:Faizan Imtiaz } & \begin{tabular}{|l|r|} 
& Gender: Male \\
\end{tabular} \\
\hline \multicolumn{3}{|c|}{ Section-1: Organizational Profile } \\
\hline 1. & Please select your position in the organization. & $\begin{array}{l}\text { (a) Director (b) Project Manager (c) Site Engineer } \\
\text { (d) Quality Control Engineer (e) Other }\end{array}$ \\
\hline 2. & Please select the type of your organization. & (a) Client (b) Contractor (c) Consultant \\
\hline 3. & Please select your qualification level. & (a) $\mathrm{PhD}$ (b) Masters (c) BSc (d) Diploma \\
\hline 4. & Please select in years your overall experience within the construction industry? & (a) $<5$ years (b) $5-10$ years $($ c) $>10$ years $($ d) $>20$ years \\
\hline 5. & Please select the number of years' you have been employed by your current company? & (a) $<5$ years (b) $5-10$ years $($ c) $>10$ years $($ d) $>20$ years \\
\hline \multicolumn{3}{|c|}{ Section-2: Common Quality Control Practices in Construction Sector } \\
\hline 6. & Have you used any form of quality management system in the construction industry? & (a) Yes (b) No \\
\hline 7. & $\begin{array}{l}\text { Have you ever been communicated or advised about quality management from senior } \\
\text { management in your current project? }\end{array}$ & (a) Yes (b) No \\
\hline 8. & Are you currently using any of these quality management systems on your project? & $\begin{array}{l}\text { (a) ISO } 9000 \text { (b) Custom (c) Client (d) Checklist (e) Specialist Sub Contractor } \\
\text { System (f) None }\end{array}$ \\
\hline 9. & $\begin{array}{l}\text { Do you use any of the following activities in order to ensure quality in your current } \\
\text { project? }\end{array}$ & $\begin{array}{l}\text { (a) Quality Planning (b) Pre-Established Criteria (c) Predefined Personnel Authority } \\
\text { (d)Quality Control Technique (e) Snagging (f) All of the above (g) None of the above }\end{array}$ \\
\hline 10. & Do you use a quality register on site? & (a) Weekly (b) Fortnightly (c) Monthly (d) Sporadically (e) Never \\
\hline 11. & $\begin{array}{l}\text { In direct comparison to that of health and safety on site; please give your opinion on the } \\
\text { importance of quality management in your construction project. }\end{array}$ & (a) More (b) Same (c) Less \\
\hline 12. & $\begin{array}{l}\text { How do you rate the attention of your company gives to quality management in } \\
\text { comparison to that of H\&S? }\end{array}$ & (a) More (b) Same (c) Less \\
\hline 13. & $\begin{array}{l}\text { Do you think each site should have a quality manager responsible for implementing } \\
\text { quality plans and checklists? }\end{array}$ & (a) Yes (b) No \\
\hline 14. & $\begin{array}{l}\text { Do you feel that a quality management system is a necessity for the site team to deliver } \\
\text { a project with zero defects? }\end{array}$ & (a) Strongly Agree (b) Agree (c) Neutral (d) Disagree (e) Strongly Disagree \\
\hline 15. & In a typical working week; do you feel that spending time to ensure quality is important? & (a) Strongly Agree (b) Agree (c) Neutral (d) Disagree (e) Strongly Disagree \\
\hline 16. & Have you ever received training in any form of quality management system & a) $\mathrm{Y}$ es b) $\mathrm{No}$ \\
\hline 17. & Do you feel site managers need to be trained in quality management skills? & (a) Yes (b) No \\
\hline 18. & $\begin{array}{l}\text { Would you be spending more time to achieve zero defects if there were incentives } \\
\text { provided to you? }\end{array}$ & (a) Yes (b) No \\
\hline 19 & $\begin{array}{l}\text { Do you agree quality management systems help reduce defective work and the number } \\
\text { of snag corrections in your current project? }\end{array}$ & (a) Yes (b) No \\
\hline \multicolumn{3}{|c|}{ Section-3: Experience of Respondents in Quality Management System } \\
\hline 21. & $\begin{array}{l}\text { How much } \% \text { of construction money can be saved by using quality control } \\
\text { management? }\end{array}$ & (a) $5 \%$ (b) $10 \%$ (c) $15 \%$ (d) more than $15 \%$ \\
\hline 22. & $\begin{array}{l}\text { To get excessive workability of concrete how much extra water, workers are adding } \\
\text { during pouring of concrete? }\end{array}$ & (a) $0.5 \%$ (b) $1.0 \%$ (c) $1.5 \%$ (d) $2 \%$ or more \\
\hline 23. & $\begin{array}{l}\text { For how much time workers use vibrator to get the proper and standard compaction of } \\
\text { concrete for good quality? }\end{array}$ & (a) 2 mint (b) 3 mint (c) more than 3 mint (d) No vibration \\
\hline 24. & When scheduling and monitoring is done at site? & $\begin{array}{l}\text { (a) At start of activity (b) In the mid of Activity } \\
\text { (c) At the end of activity (d) Not done }\end{array}$ \\
\hline 25. & Which planning software are you using? & (a) P6 (b) MS Project (c) CPM (d) PERT (e) TILOS \\
\hline 26. & $\begin{array}{l}\text { What } \% \text { age of second class brick you use in your construction with respect to first } \\
\text { class bricks? }\end{array}$ & (a) $20 \%$ (b) $30 \%$ (c) $50 \%$ (d) More than $50 \%$ \\
\hline 27. & What is the water absorption of bricks that you have used at particular project site? & (a) $20 \%$ (b) $22 \%$ (c) $24 \%$ (d) Test not performed \\
\hline 28 & $\begin{array}{l}\text { If quality control practice is carried out at your site, then what is the tolerance limit from } \\
\text { standards? }\end{array}$ & (a) $5 \%$ (b) $10 \%$ (c) More stringent than standards (d) more than 10 \\
\hline 29. & At your project what is the $\%$ age of soil compaction you get? & (a) $95 \%$ (b) $90 \%$ (c) $85 \%$ (d) less than $85 \%$ \\
\hline 30. & Is soil investigation test is carried out for your site? & (a) Yes (b) No \\
\hline 30. & After how many days you carry out test on concrete? & (a) 7 (b) 14 (c) 28 (d) no test \\
\hline 31. & For how much time concrete batching plant revolve for concrete production? & (a) 1 mint (b) 2 mint (c) $3 \operatorname{mint}$ (d) $4 \operatorname{mint}$ \\
\hline 32. & What $\%$ age of tensile strength ( $\left(\mathrm{fc}^{\prime}\right)$ of concrete you get at your project? & (a) $8 \%$ of fc' (b) $10 \%$ of fc' (c) $12 \%$ of fc' (d) No test \\
\hline 33. & What type of steel bar is used at your site? & $\begin{array}{l}\text { (a) Grade } 40 \text { hot rolled (b) Grade } 60 \text { Hot rolled (c) Grade } 40 \text { cold twisted } \\
\text { (d) Grade } 60 \text { Cold twisted }\end{array}$ \\
\hline 34. & Which quality of mixing water you used at your site & (a) Tap water (b) Distilled water (c) any quality (d) never checked quality \\
\hline \multicolumn{3}{|c|}{ Section-4: Remarks and Suggestions } \\
\hline 35 . & \multicolumn{2}{|c|}{ Please notify us about what, in your point of view, is vital to improve quality control management in construction industry of Pakistan? } \\
\hline \multicolumn{3}{|c|}{$\begin{array}{l}\text { In my opinion the selection of good quality materials is the first and important step for the quality assurance. And then fair supervision of projects according to the standards is required. } \\
\text { As construction projects are completed after the huge investment and long duration so any carelessness or corruption may not be acceptable from supervisors, contractors \& client. However, } \\
\text { think the complete control of materials quality and implementation of quality control management system with seriousness and sincerity will be possible if the anti-corruption departments will tak } \\
\text { action against corruption. }\end{array}$} \\
\hline
\end{tabular}

Mehran University Research Journal of Engineering \& Technology, Volume 38, No. 1, January, 2019 [p-ISSN: 0254-7821, e-ISSN: 2413-7219] 


\section{CONCLUSIONS}

The following conclusions are made on the basis of whole research.

(i) The level of the contractor's performance, the project monitoring and controlling techniques, client's satisfaction and workers experience in construction industry was assessed and found not in line with QMS international standards.

(ii) It is concluded that human ability is important factor of QC and it is found that most of the respondents were BSc Civil Engineers having experience less than five years and most of site engineers are doing the QC practice. Therefore, more efficient, educated, experienced and skilled staff is required to achieve the high level of quality at construction sites in Pakistan.

(iii) The implementation of any defined standard ultimately changes the culture, strategic priorities, processes and beliefs of organization. Quality performance in all construction phases is associated with the proper implementation of QC management system. On the basis of results of this survey it is concluded that the overall performance of QC activities is not so much poor in Pakistan. However, there is still much required to come in line with international practices.

(iv) The commonly used QMS standard is ISO-9000 and checklists are commonly used method. However, few contractors ensure quality because of the presence of clients and consultants. The use of regular quality register, enough time and attention must be required to control the quality. (v) Adequate training for QC is very important for better implementation of QMS. Defective work at site can be controlled with proper QMS. Promotions and incentives must be offered on the basis of good quality work.

(vi) The selection of materials according to design and environmental requirements are most significant task that determines the quality of construction directly.

(vii) The complete information about the water quantity to increase the concrete workability, vibrator time for proper compaction of concrete, project planning tools, quality of bricks on the basis of water absorption test, the range of acceptable tolerance, value of soil compaction test, quality of concrete on the basis of compressive and tensile strength, revolving time, water quality and preferred steel grade was investigated. On the basis of this section it is concluded that mostly construction companies are following standards methods but it is not the common practice of every firm.

(viii) It is found that many contractors compromised on quality and they do not achieve standard values and parameters in testing and construction processes. Moreover, there is no trend of inspection of materials in a few organizations.

\section{RECOMMENDATIONS}

Following recommendations are concluded on the basis of result of present study.

(i) Training is required to improve the skills and increase the attention of workers. 
(ii) The department of QC under the supervision of quality manager is necessary to manage all QC activities and issues.

(iii) It is required to approve the separate budget for quality assurance. It is the responsibility of regulatory authorities to play significant role for the implementation of standard methods.

(iv) It is need to establish the advanced testing labs and the contractors should be forced to use only recommended labs.

(v) Health and safety training program must be organized to ensure the safety of workers. Also, it is need to hire the safety engineer on construction site like other engineering sectors. Innovative and recent quality management standards are supportive for QA.

It is important to consider all uncertainties and sudden changes before the start of project. The mathematical models such as charts, set of equations, diagrams etc. must be used to simplify the data. It is needed to encourage the technical and managerial skilled person. The systematic process must be implemented to minimize the project time, cost and errors.

(vii) Future research must be conducted to indicate the problems in implementation of QMS and certification from foreign bodies such as ISO.

(viii) Future research must be conducted for the development of QC model or plan for each construction sector.

(ix) In future studies it is also need to consider the already implemented QC systems and approaches adopted in developing countries for the selection of suitable model.

\section{ACKNOWLEDGEMENT}

Authors are thankful to the Infrastructure Development Authority Punjab, Government of Punjab, Pakistan, for providing necessary facilities to complete this study.

\section{REFERENCES}

[1] Pheng, L.S., and Jasmine, A.T., "Implementing Total Quality Management in Construction Firms", Journal of Management in Engineering, Volume 20, No. 1, pp. 8-15, 2004.

[2] Love, P.E.D., Mandal, P., and Li, H., "Determining the Casual Structure of Rework Influences in Construction", Construction Management and Economics, Volume 17, No. 4, pp. 505-517, 1998.

[3] Benavides-Velasco, C.A., Quintana-García, C., and Marchante-Lara, M., “Total Quality Management, Corporate Social Responsibility and Performance in the Hotel Industry”, International Journal of Hospitality Management, Volume 41, pp.77-87, 2014.

Burati, J.L., and Oswald, T.H., "Implementing Total Quality Management in Engineering and Construction”, Journal of Management in Engineering, pp. 456-470, 1993.

[5] Hoseini, A.G., Zhang, T., Nwadigo, O., Hoseini, A.H.G., Naismith, N., Tookey, J., and Raahemifar, K., "Application of BIM Integrated Knowledge-based Building Management Systemfor Inspecting PostConstruction Energy Efficiency", Renewable and Sustainable Energy Review, Volume 72, pp. 935-949, 2017.

[6] Idris, M.A., McEwan, W., and Belavendram, N., "The Adoption of ISO 9000 and Total Quality Management in Malaysia", The TQM Magazine,Volume 8, No. 5, pp. 65-68, 1996.

[7] Paulet, E., "Financial Markets and the Banking Sector: Roles and Responsibilities in a Global World", Routledge, 2015 . 
[8] Kärnä, S., “Analyzing Customer Satisfaction and Quality in Construction- The Case of Public and Private Customers", Nordic Journal of Surveying and Real Estate Research, Volume 2, 2014.

Alzahrani, J.I., and Emsley, M.W., "The Impact of Contractors' Attributes on Construction Project Success: A Post Construction Evaluation", International Journal of Project Management, Volume 31, No. 2, pp. 313-322, 2013.

[10] Abd-Hamid, Z., Azizan, N.A., and Sorooshian, S., "Predictors for the Success and Survival of Entrepreneurs in the Construction Industry", International Journal of Engineering Business Management, Volume 7, No. 1 pp.1-11, 2015 .

[11] Atout, M.M., "The Influence of Construction Manager Experience in Project Accomplishment", Management Studies, Volume 2, No. 8, pp. 515-532, 2014.

O'Connor, T.J., and Young, R.L., "Impact of Integration and Automation Technology on Project Success Measures", Proceedings of $4^{\text {th }}$ Joint International Symposium on Information Technology in Civil Engineering Nashville, Tennessee, 2014.

[14] Chan, A., Scott, D., and Lam, E., "Framework of Success Criteria for Design/Build Projects", Journal of Management Engineering, Volume 18, No, 3, pp. 120-128, 2002.

[15] Chou, J., Irawan, N., and Pham, A., "Project Management Knowledge of Construction Professionals: Cross-Country Study of Effects on Project Success", Journal of Construction Engineering Management, Volume 139, No, 11, pp. 1-15, 2013.

[16] Junying, L., and Jiang, X., "Study on Construction Quality Control of Urban Complex Project Based on BIM", Procedia Engineering, Volume 174, pp. 668-676, 2017.
[17] Lukichev, C.S., and Romanovich, M., "The Quality Management System as a Key Factor for Sustainable Development of the Construction", Procedia Engineering, Volume 165, pp. 1717-1721, 2016.

[18] Poyhonena, P., Sivunena, M., and Kajandera, J-K., "Developing a Project Delivery System for Construction Project - ACase Study", Procedia Engineering, Volume 161, pp. 711-715, 2016.

[19] Kozlovskaa, M., Mackovab, D., and Spisakovac, M., "Survey of Construction Management Documentation Usage in Planning and Construction of Building Project", Procedia Engineering, Volume 161, pp. 813-822, 2016.

[20] Memon, N.A., Abro, Q.M.M., and Mugheri, F., "Quality Management in the Design and Construction Phase: A Case Study", Mehran University Research Journal of Engineering \& Technology, Volume 30, pp. 511-520, Jamshoro, Pakistan, 2011.

[21] Goetsch, D.L., and Davis, S.B., "Introduction to Total Quality: Quality Management for Production, Processing and Services", Prentice-Hall, Englewood Cliffs, NJ, 1997.

[22] Carter, M.Z., Armenakis, A.A., Feild, H.S., and Mossholder, K.W., "Transformational Leadership, Relationship Quality, and Employee Performance during Continuous Incremental Organizational Change", Journal of Organizational Behavior, Volume 34, No. 7 , pp. 942-958, 2013.

[23] Talib, F., Rahman, Z., and Qureshi, M.N., "Analysis of Interaction Among the Barriers to Total Quality Management Implementation Using Interpretive Structural Modeling ApproachBenchmarking" An International Journal, Volume 18, No. 4, pp. 563-587, 2011.

[24] Dadfar, H., Brege, S., and Sarah E.S.S., "Customer Involvement in Service Production, Delivery and Quality: The Challenges and Opportunities", International Journal of Quality and Service Sciences, Volume 5, No. 1, pp. 46-65, 2013.

[25] Fuertes, A., Casals, M., Gangolells, M., Forcada, N., Macarulla, M., and Roca, X., “An Environmental Impact Causal Model for Improving the Environmental Performance of Construction Processes", Journal of Cleaner Production, Volume 52, pp. 425-437, 2013. 
[26] McCabe, S., "Quality Improvement Techniques in Construction: Principles and Methods", Routledge, 2014.

Mitra, A., "Fundamentals of Quality Control and Improvement”, John Wiley \& Sons, 2016.

Osabiya, B.J., "The Effect of Employee's Motivation on Organizational Performance", Journal of Public Administration and Policy Research, Volume 7, No. 4, pp. $62-75,2015$

Alagaraja, M., "A Conceptual Model of Organizations as Learning-Performance Systems: Integrative Review of Lean Implementation Literature", Human Resource Development Review, Volume 13, No. 2, pp. 207-233, 2014.

[30] Abdulhasan, J.S., "Towards Establishing a Quality Management System Based on ISO-9000 Requirements in the Iraqi Military Construction Organization”, Ph.D. Thesis, University Sains, Malaysia, 2016.

[31] Yitmen, I., "Organizational Cultural Intelligence: ACompetitive Capability for Strategic Alliances in the International Construction Industry", Project Management Journal, Volume 44, No. 4, pp. 5-25, 2013.
Bon, A.T., and Mustafa, E.M., "Impact of Total Quality Management on Innovation in Service Organizations: Literature Review and New Conceptual Framework", Procedia Engineering, Volume 53, pp. 516-529, 2013.

[33] Safa, M., Shahi, A., Haas, C.T., and Hipel, K.W., "Supplier Selection Process in an Integrated Construction Materials Management Model", Automation in Construction, Volume 48, pp. 64-73, 2014.

[34] Oladirin, O.T., Olatunji, S.O., and Hamza, B.T., "Effect of Selected Procurement Systems on Building Project Performance in Nigeria", International Journal of Sustainable Construction Engineering and Technology, Volume 4, No. 1, pp. 48-62, 2013.

[35] Dëjus, T., and Antucheviciene, J., "Assessment of Health and Safety Solutions at a Construction Site", Journal of Civil Engineering and Management, Volume 19, No. 5, pp. 728-737, 2013.

[36] Kiruja, E.K., and Mukuru, E., "Effect of Motivation on Employee Performance in Public Middle Level Technical Training Institutions in Kenya”, International Journal of Advances in Management and Economics, Volume 2, No. 4, pp. 73-82, 2013.

[37] Pacheco-Torgal, F., "Eco-Efficient Construction and Building Materials Research", Construction and Building Materials, Volume 51, pp. 151-162, 2014. 